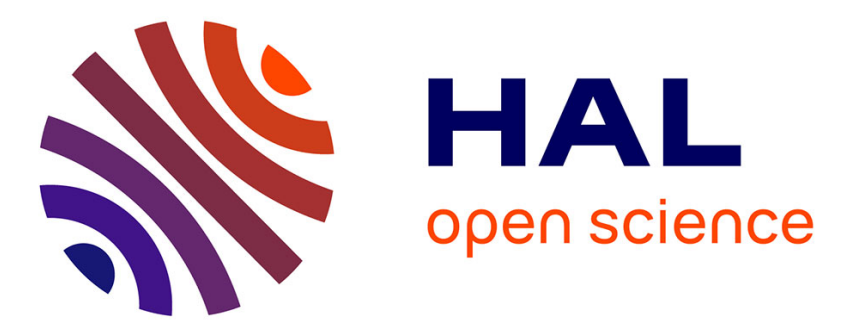

\title{
Isokinetic testing of evertor and invertor muscles in patients with chronic ankle instability.
}

Pascal David, Mohamad Halimi, Isabelle Mora, Pierre-Louis Doutrellot, Michel Petitjean

\section{- To cite this version:}

Pascal David, Mohamad Halimi, Isabelle Mora, Pierre-Louis Doutrellot, Michel Petitjean. Isokinetic testing of evertor and invertor muscles in patients with chronic ankle instability.. Journal of Applied Biomechanics, 2013, 29 (6), pp.696-704. hal-01024094

\section{HAL Id: hal-01024094 \\ https://hal.science/hal-01024094}

Submitted on 15 Jul 2014

HAL is a multi-disciplinary open access archive for the deposit and dissemination of scientific research documents, whether they are published or not. The documents may come from teaching and research institutions in France or abroad, or from public or private research centers.
L'archive ouverte pluridisciplinaire HAL, est destinée au dépôt et à la diffusion de documents scientifiques de niveau recherche, publiés ou non, émanant des établissements d'enseignement et de recherche français ou étrangers, des laboratoires publics ou privés. 
Note. This article will be published in a forthcoming issue of the Journal of Applied Biomechanics. The article appears here in its accepted, peer-reviewed form, as it was provided by the submitting author. It has not been copyedited, proofread, or formatted by the publisher.

Section: Original Research

Article Title: Isokinetic Testing of Evertor and Invertor Muscles in Patients with Chronic Ankle Instability

Authors: Pascal David ${ }^{1}$, Mohamad Halimi ${ }^{2}$, Isabelle Mora ${ }^{*}$, Pierre-Louis Doutrellot ${ }^{3}$ and Michel Petitjean ${ }^{1,4}$

Affiliations: ${ }^{1}$ EA 2931 Biomécanique et Physiologie des Mouvements Naturels et des Gestes Sportifs, Université de Paris Ouest Nanterre La Défense, Nanterre, France. ${ }^{2}$ Institut de Physiothérapie, Université Saint Joseph, Beirut, Lebanon. ${ }^{*}$ In memoriam. ${ }^{3}$ Service de Médecine Physique et de Rééducation, Centre Hospitalier Universitaire d'Amiens-Picardie, Amiens, France. ${ }^{4}$ Service d'Explorations Fonctionnelles du Système Nerveux, Centre Hospitalier Universitaire d'Amiens-Picardie, Amiens, France.

Journal: Journal of Applied Biomechanics

Acceptance Date: January 9, 2013

(C)2013 Human Kinetics, Inc. 


\title{
Isokinetic Testing of Evertor and Invertor Muscles
}

\section{in Patients with Chronic Ankle Instability}

\author{
Pascal David ${ }^{1}$, Mohamad Halimi ${ }^{2}$, Isabelle Mora ${ }^{*}$, Pierre-Louis Doutrellot ${ }^{3}$ and Michel \\ Petitjean $^{1,4}$ \\ ${ }^{1}$ EA 2931 Biomécanique et Physiologie des Mouvements Naturels et des Gestes Sportifs, \\ Université de Paris Ouest Nanterre La Défense, Nanterre, France \\ ${ }^{2}$ Institut de Physiothérapie, Université Saint Joseph, Beirut, Lebanon \\ In memoriam \\ ${ }^{3}$ Service de Médecine Physique et de Rééducation, Centre Hospitalier Universitaire \\ d'Amiens-Picardie, Amiens, France \\ ${ }^{4}$ Service d'Explorations Fonctionnelles du Système Nerveux, Centre Hospitalier \\ Universitaire d'Amiens-Picardie, Amiens, France
}

Funding: No financial assistance was received for this study.

Conflict of Interest Disclosure: The authors declare that they have no proprietary, financial, professional or other personal interest of any nature or kind in any product, service and/or company that could be construed as influencing the position presented in the manuscript.

Corresponding Address: Pascal David

E-mail address: pascal.david@u-picardie.fr (P. David).

Running Title: isokinetic testing of ankle muscles

Word Count: 3929 words (excluding title, abstract, tables/figures, figure legends,

Acknowledgements, and References) 
"Isokinetic Testing of Evertor and Invertor Muscles in Patients with Chronic Ankle Instability" by David P et al. Journal of Applied Biomechanics

(C) 2013 Human Kinetics, Inc.

\section{Abstract}

Ankle sprains are among the most common sport-related injuries and can lead to chronic ankle instability. Impaired sensorimotor function of the ankle musculature is often suggested as a cause. The present study sought to assess and compare the isokinetic performance and electromyographic patterns of evertor and invertor muscles in patients with chronic ankle instability and in a control group. Twelve patients with chronic ankle instability and twelve healthy subjects were included. Isokinetic eccentric and concentric testing at various angular velocities was performed for eversion and inversion movements. The corresponding myoelectric activities of the fibularis longus and tibialis anterior muscles were quantified from surface electromyographic recordings by computing average root mean square values. Patients had lower myoelectric activity of the evertor and invertor muscles than controls did; this difference could account for the eccentric weakness associated with ankle instability. Functional strength ratios revealed a dynamic strength imbalance in unstable ankle patients and that may contribute to recurrent injury. Our findings suggest that rehabilitation programs for unstable ankle patients must be focused on the motor control of eccentric contractions of the ankle evertors and invertors, in order to boost these muscles' contribution to ankle stabilization.

Keywords: ankle injuries; biomechanics; electromyography; rehabilitation 
"Isokinetic Testing of Evertor and Invertor Muscles in Patients with Chronic Ankle Instability" by David P et al. Journal of Applied Biomechanics

(C) 2013 Human Kinetics, Inc.

\section{Introduction}

Inversion ankle sprains are among the most prevalent sport-related injuries. ${ }^{1}$ The most common complication following an initial ankle sprain (occurring in $40 \%$ to $70 \%$ of patients) is the persistence of residual symptoms. ${ }^{2}$ These residual symptoms (including pain, swelling and "giving way" of the ankle joint) have been collectively referred to as chronic ankle instability (CAI). CAI is prevalent in athletics, especially volleyball, and is thought to affect the learning and performance of motor skills. ${ }^{3}$ Despite extensive research on the factors that contribute to $\mathrm{CAI},{ }^{4}$ the persistence of this condition in patients having one or more initial ankle injuries emphasizes the need for biomechanical investigations in order to (i) promote appropriate, personalized rehabilitation and prevention programs and (ii) break the vicious cycle of recurrent sprains.

Mechanical and functional instability can contribute to CAI. ${ }^{5}$ Mechanical instability refers to movement beyond the ankle's physiologic range of motion, whereas functional instability describes the subjective feeling of ankle instability and/or recurrent ankle sprains due to proprioceptive and/or neuromuscular impairments. ${ }^{6}$ Of the neuromuscular contributing factors associated with CAI, weakness of the evertor and invertor muscles involved in lateral motion of the foot is frequently suggested (notably since the introduction of isokinetic testing devices). ${ }^{7}$ The latter are widely used in both laboratory settings and clinical practice to assess levels of muscle performance and/or a rehabilitation program's state of progress. Despite the large body of literature dedicated to this topic, there is no consensus on the relationship between ankle muscle strength (especially evertor strength) and CAI in terms of the contraction mode, torque values and torque ratios. ${ }^{8,9}$ Hence, these discrepancies concerning the relationship between impaired eversion strength and residual instability warrant further investigation. 
"Isokinetic Testing of Evertor and Invertor Muscles in Patients with Chronic Ankle Instability" by David P et al. Journal of Applied Biomechanics

(C) 2013 Human Kinetics, Inc.

Several studies have highlighted the presence of impairments in both the peripheral and central nervous control of the ankle musculature in patients with CAI. ${ }^{10-12}$ Indeed, it has been suggested that peripheral sensorimotor impairments can explain proprioceptive deficiencies (particularly in the inversion direction), ${ }^{13}$ lower musculotendinous stiffness ${ }^{14}$ and impaired postural control during functional activities. ${ }^{15,16}$ Likewise, alterations in gait initiation $^{12}$ or motoneuron pool excitability ${ }^{17,18}$ have been found in patients with CAI, suggesting the presence of changes in spinal and supraspinal motor control mechanisms. However, the respective roles of mechanical muscle impairments and central nervous system factors in CAI are not defined.

In this context, the neuromuscular system's functional status can be assessed by simultaneously applying biomechanical and neurophysiological methods. ${ }^{19}$ To better evaluate the potential involvement of one or more of the above-mentioned causes, we sought to establish whether or not the relationship between electromyographic activity and torque exerted by the ankle muscles is impaired in patients with CAI. Accordingly, the study's objective was to assess and compare isokinetic performance and electromyographic patterns for ankle evertor and invertor muscles in CAI patients and a control group.

\section{Methods}

\section{Participants}

A total of 24 patients and controls volunteered to participate in this non-invasive study. All participants completed the Ankle Instability Instrument. ${ }^{20}$ The Ankle Instability Instrument (AII) is a 12-item questionnaire used to determine the presence or absence of CAI, based on the following factors: the severity of the initial ankle sprain, a history of ankle instability and instability during activities of daily living. The CAI group included 12 patients with a history of at least one substantial ankle sprain requiring a period of weight-bearing assistance or immobilization, the presence of "giving way" episodes, feelings of ankle joint 
"Isokinetic Testing of Evertor and Invertor Muscles in Patients with Chronic Ankle Instability" by David P et al. Journal of Applied Biomechanics

(C) 2013 Human Kinetics, Inc.

instability, and lastly, pain during recreational or sports activities. These requirements have been used previously as inclusion criteria for patients with CAI. ${ }^{2}$ The number of prior sprains per patients ranged from 1 to 6 , with an average of 3 . The duration of residual symptoms following the initial ankle sprain ranged from 2 to 8 years, with an average of $4.8 \pm 1.9$ years. The CAI patients reported an average of $6 \pm 1$ "yes" responses on the AII. Subjects were excluded if they had (i) reported an ankle sprain or participated in a rehabilitation program for the affected ankle within the 3 months preceding the study, (ii) a history of surgery for fracture of either leg or (iii) a history of any neurological disease known to affect strength. For patients with bilateral ankle instability, the ankle which presented more pain, greater performance limitation and/or more recurrent sprains was considered to be the more unstable ankle. By applying the AII, we were able to detect the ankle for assessment in CAI patients. In all cases, this side corresponded to the non-dominant leg (as revealed by kicking preference). Twelve subjects with no history of ankle sprain or neuromuscular disorders were included in the control group. The study protocol had received prior approval from the local independent ethics committee. Prior to testing, each participant was fully informed of the study's aims and procedures, in accordance with the French legislation on biomedical research and the stipulations of the latest update of the 1964 Declaration of Helsinki. The participants' biometric characteristics are presented in Table 1.

\section{Isokinetic torque measurements}

All participants performed ankle eversion and inversion contractions with a calibrated Cybex Norm ${ }^{\circledR}$ isokinetic dynamometer (Lumex Inc., Ronkonkoma, NY), which recorded the instantaneous muscle torque at various preset, constant, angular velocities. For the two groups, inversion-eversion movements were analyzed for the non-dominant leg. Prior to testing, subjects were installed comfortably on the Cybex in a semirecumbent position and a seatback angle of $25^{\circ}$ to the horizontal. The (bare) foot to be tested was placed on the unit's 
"Isokinetic Testing of Evertor and Invertor Muscles in Patients with Chronic Ankle Instability" by David P et al. Journal of Applied Biomechanics

(C) 2013 Human Kinetics, Inc.

inversion/eversion footplate. The unit's rotational axis coincided with the functional axis of the subtalar joint complex, with an inclination of $35^{\circ}$ with respect to the posterior surface plate. The dynamometer head was positioned in about $60^{\circ}$ of posterior tilt. The foot was placed with $10^{\circ}$ of ankle plantar flexion and the subtalar joint was placed in a neutral position. Dynamometer and chair adjustments were made to line up the midline of the foot with the middle of the patella; hence, the tibial crest was approximately horizontal over its entire length. The hip and knee were positioned in $60^{\circ}$ and $90^{\circ}$ of flexion, respectively. Correct positioning of the tested limb was checked with a handheld goniometer. In order to support and secure the legs in the defined position and limit extraneous motions, a harness was placed over the hip. A pad strapped beneath the distal thigh maintained the knee and a stand with belts supported the leg at its distal part. To prevent the sole of the foot from moving on the plate, the tested foot was secured with two crossed straps. The dynamometer's torque, angular velocity and position data outputs (range $\pm 10 \mathrm{~V}$ ) were sampled at $1000 \mathrm{~Hz}$ using a 12-bit analog-to-digital converter and then stored on a computer for off-line processing. Gravity correction was estimated by the Cybex software. Prior to each recording session, the dynamometer was calibrated according to the manufacturer's recommended procedure.

\section{Electromyographic recordings}

Electromyographic (EMG) signals were recorded from the fibularis longus and tibialis anterior muscles in a bipolar mode using two $8 \mathrm{~mm}$-diameter silver chloride surface electrodes (Beckman, Fullerton, CA). Pairs of electrodes were placed $20 \mathrm{~mm}$ (centre-tocentre) over muscles' bellies and along the muscle fiber axis. ${ }^{21}$ The skin surface was carefully shaved, abraded and cleaned with alcohol before electrode placement, so that the impedance of the skin-electrode interface was below $5 \mathrm{k} \Omega$. A ground electrode was placed on the ipsilateral lateral malleolus. The two EMG signals were sent to a bipolar multi-channel 
"Isokinetic Testing of Evertor and Invertor Muscles in Patients with Chronic Ankle Instability" by David P et al. Journal of Applied Biomechanics

(C) 2013 Human Kinetics, Inc.

amplifier (Gould 6600, Gould Electronics, Eichstetten, Germany; common mode rejection rate: $95 \mathrm{~dB}$; input impedance: $100 \mathrm{M} \Omega$ ), with a bandwidth frequency ranging from 10 to 500 $\mathrm{Hz}$ and a gain adjusted to between 1000 and 5000. Electromyographic signals were sampled at $1000 \mathrm{~Hz}$ using the same 12-bit analog-to-digital converter and then stored on the computer for off-line processing. Consequently, all data sets (whether electromyographic or mechanical) were collected synchronously throughout the whole range of motion.

\section{Experimental procedure}

The first part of the experimental session was devoted to learning and warming up; the subjects were familiarized with the apparatus and the testing procedure (particularly in the eccentric mode and the eversion movement) for about 15 minutes. Prior to the isokinetic strength test on the Cybex dynamometer, the subjects performed a 5-minute warm-up exercise on a cycle ergometer. They then performed several submaximal, isokinetic muscle actions using test velocities at their self-perceived 50\% of maximal effort. Under concentric conditions, the subjects were instructed to turn (push) the lever arm throughout the full range of motion in both inversion and eversion movements. Under eccentric conditions, the subjects were instructed to actively resist the lever arm that drove the ankle from the initial position in both inversion and eversion movements. Isokinetic muscle movements were performed throughout the subject's active range of motion (i.e. maximal inversion and eversion minus $10^{\circ}$ for both directions). The second part of the experimental session started after a 5-minute rest period. Subjects had to perform eight maximal inversion-eversion contractions under concentric conditions (at $60 \%$ s and $120 \%$ s) and under eccentric conditions (at $-30 \%$ s, $-60 \%$ and $-90 \%$ s). The order of measurements was randomly assigned. The subjects were verbally encouraged to make a maximal effort as fast as possible throughout the full range of motion. ${ }^{22}$ To ensure standardization, the same investigator performed all the tests. Visual feedback (which is known to enhance performance) was provided in real time via the 
"Isokinetic Testing of Evertor and Invertor Muscles in Patients with Chronic Ankle Instability" by David P et al. Journal of Applied Biomechanics

(C) 2013 Human Kinetics, Inc.

dynamometer's computer screen, ${ }^{23}$ which was located approximately $80 \mathrm{~cm}$ in front of the subject at eye level. To prevent the occurrence of significant muscle fatigue, a 1-minute rest period was imposed between each set of concentric and eccentric contractions. ${ }^{24}$

\section{Data analysis}

Off-line signal processing was performed by using custom routines written in Matlab 6.5 (The Mathworks, Inc., Natick MA). Electromyographic and isokinetic data were analyzed over the isokinetic (i.e. constant angular velocity) phase of movement, determined on the basis of the velocity signal. For each angular velocity, the highest isokinetic torque output was selected as the peak torque value. Mean peak torque values were then calculated from the best 6 of the 8 trials and divided by (i.e. normalized against) the subject's body weight. This normalization was performed in order to reduce inter-individual variability. Reciprocal contraction-mode ratios for both evertors (Ev E/C) and invertors (Inv E/C) and reciprocal muscle-group ratios (expressed as Eev/Cinv and Cev/Einv) were calculated from the mean peak torque values (normalized against body weight) measured during movements at $60 \%$ s. The post-processing of raw EMG data included offset correction and full-wave rectification using an absolute function. During each contraction, myoelectrical activities were quantified by computing the root mean square (RMS) value of the raw EMG signal every $100 \mathrm{~ms}$ over the period of interest. Average RMS values were then determined by calculating the mean of the 6 trials. For each muscle, the average RMS values were then expressed as follows:

$R M S(\%)=\frac{R M S_{v}}{R M S_{60 c o n}} \times 100$, where $R M S_{v}$ is the average RMS value at a given velocity ($30 \%$ s, $-60 \%$ s, $-90 \%$ s, $60 \%$ s and $120 \%$ s) and $R M S_{60 c o n}$ is the average RMS value in a $60 \%$ concentric contraction (where the muscle acts as an agonist). ${ }^{25}$ To express each muscle's torque generation capacity and thus gain information on potentially CAI-related variations in torque and muscle activity, the torque-to-EMG ratio was calculated as follows: 
"Isokinetic Testing of Evertor and Invertor Muscles in Patients with Chronic Ankle Instability" by David P et al.

Journal of Applied Biomechanics

(C) 2013 Human Kinetics, Inc.

$\frac{\text { torque }_{v}}{\operatorname{RMS}(\%)}$, where torque $_{v}$ is the average peak torque value (in $\mathrm{Nm}$ ) at a given velocity (as described above) and $R M S(\%)$ is the corresponding, normalized RMS value.

\section{Statistical analysis}

Data distributions were checked for normality using a Kolmogorov-Smirnov test and for equality of variance using a Fisher-Snedecor test. Non-normally distributed data were logtransformation. For each muscle, a multivariate analysis of variance (MANOVA) with repeated measures on angular velocity was used to analyze changes in the outcome measures (torque, RMS and torque-to-EMG ratio) as a function of ankle stability status and the contraction mode. For effects that were statistically significant in the MANOVA, follow-up analyses included a univariate analysis of variance (ANOVA). Tukey honestly significant difference testing was used for post-hoc comparisons. Functional ratios (Ev E/C and Inv E/C) were analyzed in a two-way ANOVA (movement [eversion versus inversion] $\times$ group [CAI versus control]). Independent-samples $t$ tests were used to assess the significance of intergroup differences in functional ratios (Eev/Cinv and Cev/Einv). The threshold for statistically significance was set to $P<.05$. A post-hoc power and effect size analysis was performed when a difference in the dependent variables due to CAI was observed. The effect size was estimated as follows: $\left(M_{1}-M_{2}\right) /$ opooled, where $M_{1}-M_{2}$ was the difference in mean values between the two groups and opooled was the average population standard deviation. The strength of effect sizes was interpreted according to Cohen's guidelines ${ }^{26}$ $(\leq 0.4$ : small; 0.41 to 0.7 : moderate; $>0.7$ : strong). Data are presented as mean \pm standard deviation. All data analyses were performed with Statview software (SAS institute, Inc, Cary, NC). 
"Isokinetic Testing of Evertor and Invertor Muscles in Patients with Chronic Ankle Instability" by David P et al. Journal of Applied Biomechanics

(C) 2013 Human Kinetics, Inc.

\section{Results}

There was no significant effect of gender on peak torque values for either muscle $(P>$ $.05)$. For the evertor muscle, a significant main effect of group was observed $(P<.0001)$. Torque values were significantly lower $(P<.0001$, effect size: 0.78 , power: 0.98$)$ in the CAI group than in the control group (Figure 1). For eccentric contraction, the significant intergroup difference was confirmed $(P<.0001$, effect size: 1.22). Pairwise comparisons revealed significantly lower torque values in the CAI group for all three angular velocities $(P$ $<.01)$. For concentric contraction, no significant difference was observed $(P=.106)$.

For the invertor muscle, a significant main effect of group was also observed $(P<$ $.0001)$. Torque values were significantly lower $(P<.0001$, effect size: 0.71 , power: 0.96$)$ in the CAI group than in the control group (Figure 1). For eccentric contraction, the significant intergroup difference was confirmed $(P<.0001$, effect size: 1.06). Pairwise comparisons revealed the presence of significantly lower torque values in the CAI group for all three angular velocities $(P<.01)$. For concentric contraction, no significant difference was observed $(P=.491)$.

In both groups of participants, the normalized RMS values for the fibularis longus were significantly lower $(P<.001)$ for eccentric contraction than for concentric contraction (Figure 2). Furthermore, these normalized RMS values were significantly lower $(P<.01$, effect size: 0.56 , power: 0.74 ) in the CAI group than in the control group. The significant intergroup difference was confirmed for eccentric contraction $(P<.0001$, effect size: 0.93$)$. Pairwise comparisons showed significantly lower normalized RMS values for the fibularis longus in the CAI group for all three angular velocities $(P<.05)$. No significant difference was observed in the concentric contraction mode $(\mathrm{P}=.875)$.

There was no significant difference between the normalized RMS values for the tibialis anterior obtained in eccentric contraction and those obtained in concentric contraction 
"Isokinetic Testing of Evertor and Invertor Muscles in Patients with Chronic Ankle Instability" by David P et al. Journal of Applied Biomechanics

(C) 2013 Human Kinetics, Inc.

in either group of participants (Figure 2). The normalized RMS values for the tibialis anterior were significantly lower in the CAI group than in the control group $(P<.001$, effect size: 0.62, power: 0.86). The significant intergroup difference was confirmed for eccentric contraction, $(P=.002$, effect size: 0.71$)$. Pairwise comparisons showed significantly lower normalized RMS values for the tibialis anterior in the CAI group at $-30 \%$ s and $-60 \%$ s $(P<$ .05). Similarly, there was a significant difference in the concentric contraction mode $(P<.05$, effect size: 0.57). Pairwise comparisons revealed significantly lower normalized RMS values for the tibialis anterior in the CAI group at $120 \% \mathrm{~s}(P<.05)$.

There was no significant main effect of group $(P>.60)$ on each muscle's torque-toEMG ratio (Figure 3).

A significant main effect of group was observed for evertor and invertor eccentric to concentric torque ratios (measured at $60 \% ; P<.0001$, effect size: 1.18 ). These ratios were significantly lower in the CAI group $(P<.01$, effect size: 1.21 and 1.17 for evertors and invertors, respectively) (Figure 4). There was no statistically significant main effect of movement for the evertor and invertor eccentric-to-concentric torque ratios measured at $60 \% \mathrm{~s}$ $(P=.122)$. The eccentric evertor to concentric invertor torque ratio was significantly lower in the CAI group $(P<.01$, effect size: 1.31) (Figure 4). In contrast, the concentric evertor to eccentric invertor torque ratio was significantly higher in the CAI group $(P<.05$, effect size: $0.84)$.

\section{Discussion}

The major findings of our study were that patients with CAI (i) had a dynamic strength imbalance (as evidenced by functional strength ratios) and (ii) showed lower EMG activity of the evertor and invertor muscles, in comparison with healthy subjects.

Since the pioneering work of Bosien et al. ${ }^{27}$, many studies have examined the relationship between ankle muscle strength (especially evertor strength) and CAI. Indeed, 
"Isokinetic Testing of Evertor and Invertor Muscles in Patients with Chronic Ankle Instability" by David P et al. Journal of Applied Biomechanics

(C) 2013 Human Kinetics, Inc.

lateral ankle sprains result from a combination of sudden inversion and plantar flexion of the ankle complex. ${ }^{5}$ As suggested by Munn et al. ${ }^{28}$, impairments in evertor strength may reduce these muscles' ability to dynamically control inversion and thus predispose the ankle to an inversion sprain. The present study evidenced a $22 \%$ impairment in eccentric evertor strength; this supports the findings reported by Willems et al. ${ }^{29}$. However, several recent reports indicate that evertor muscle weakness is not a common impairment in patients with $\mathrm{CAI}^{9,30}$ and thus contradict our results. On the basis of these studies, it appears that methodological differences may explain the discrepancies in isokinetic test results. One possible explanation relates to the fact that population heterogeneity (in terms of the definition of ankle instability or variations in the inclusion criteria for CAI patients) complicates the comparison and interpretation of isokinetic test data. ${ }^{2}$ Many researchers have reported only raw (and not normalized) torque values. Normalization against body weight decreases the inter-individual variability and facilitates the statistical comparison of muscle strength in subjects with differing body types and in males vs. females. From a functional point of view, normalized torque values are more relevant because the inversion moment generated at the ankle usually occurs in a closed kinetic chain and is thus influenced by body weight. ${ }^{29}$ Furthermore, many authors report bilateral comparisons for isokinetic test results (i.e. the injured side vs. the non-injured side). In our study, the CAI group was compared with a non-injured group because we hypothesized that pre-existing joint injury to one leg would inhibit the musculature of the contralateral leg (via an arthrogenic muscle response). ${ }^{31}$ In contrast, our results for the invertor muscle set are consistent with other studies having reported invertor strength impairments in patients with CAI. ${ }^{28}$ The present study reported a $24 \%$ decrease in eccentric invertor strength for the CAI group. This finding reinforces the hypothesis according to which impairments in the eccentric action of invertor muscles reduce the ability to control lateral postural sway by limiting closed chain eversion. ${ }^{28}$ 
"Isokinetic Testing of Evertor and Invertor Muscles in Patients with Chronic Ankle Instability" by David P et al. Journal of Applied Biomechanics

(C) 2013 Human Kinetics, Inc.

Although isokinetic eversion and inversion movements do not represent completely "natural" movements and test velocities are often lower than those achieved during functional activities, the information obtained from isokinetic muscle testing (peak torque and functional strength ratios) is still of value to the clinician when investigating the muscle strength of a given, isolated muscle group. Indeed, it has been suggested that CAI-associated dynamic strength imbalance can be assessed by assessing the ratio of antagonist eccentric torque to agonist concentric torque. ${ }^{28,32}$ This ratio expresses (at least from a functional point of view) a more realistic approximation of muscle activities observed in activities of daily living or as sports motor tasks, insofar as it describes the eccentric, resistive capacity of antagonist muscles in relation to the concentric motor action of agonistic muscles. The concentric evertor to eccentric invertor and the eccentric evertor to concentric invertor torque ratios calculated in our study with healthy ankles were consistent with those reported by Kaminski and Hartsell. ${ }^{32}$ Similarly, we observed a $26 \%$ decrease in the eccentric evertor to concentric invertor torque ratio for patients with CAI vs. subjects with healthy ankles. Inversely, patients with CAI displayed a $20 \%$ higher concentric evertor to eccentric invertor torque ratio; this also supports the results reported by Munn et al.. ${ }^{28}$ The functional torque ratio thus reflects the dynamic strength imbalance in patients with CAI (as evidenced by eccentric evertor and invertor strength impairments). These results are consistent with the findings of other studies having shown evertor/invertor imbalances during functional movements. ${ }^{33,34}$ During the early stance phase of the gait cycle, patients with CAI differed from controls in terms of the evertor/invertor joint moment patterns. ${ }^{33}$ Before initial contact from a single leg jump, patients with CAI demonstrated subnormal fibular EMG activity. ${ }^{34}$ According to these authors, changes in movement characteristics probably lead to a subsequent foot position fault (i.e. a more extreme inversion position) and predisposing the ankle to repeated injury. 
"Isokinetic Testing of Evertor and Invertor Muscles in Patients with Chronic Ankle Instability" by David P et al. Journal of Applied Biomechanics

(C) 2013 Human Kinetics, Inc.

They interpreted their findings as possibly reflecting changes in the feed-forward motor control associated with CAI, with modulation by spinal or supraspinal mechanisms.

Our results revealed changes in fibularis longus and tibialis anterior EMG activity in patients with CAI. During concentric contractions, the fibularis longus's EMG activities did not differ from control values. In contrast, the tibialis anterior's EMG activities were low at the highest angular velocity but there was no change in the concentric invertor torque to tibialis anterior RMS ratio. Consequently, the higher rate of invertor torque decrease with increasing angular velocity can be imputed to impaired neural control of the invertor muscles. This suggests that in CAI, the invertor muscles are less able to rapidly develop concentrically strength in response to an aberrant ankle position. A reduction in EMG activity with increasing contractile velocity has already been reported for the elbow flexor muscles and was interpreted as a change in the motor unit recruitment process influenced by proprioceptive feedback. ${ }^{35}$

In the present study, the main findings of our EMG analysis of patients with CAI were lower fibularis longus and tibialis anterior muscle activities during eccentric contraction. Insofar as the evertor torque to fibularis longus RMS and invertor torque to tibialis anterior RMS ratios were not affected by CAI, one could suggest that the associated impairment in the eccentric muscle strength is mainly related to neural adaptation. The reduction in neural drive associated with CAI could be imputed to damage to the sensory receptors within the injured ligaments and the joint capsule. ${ }^{36}$ The latter are known to play an important role in functional joint stability, since they are involved in corrective and pre-programmed motor control mechanisms. ${ }^{37}$ Decreased neural drive could also be attributed to arthrogenic muscle inhibition, which is defined as on-going neural inhibition of the uninjured musculature surrounding an injured or distended joint. ${ }^{31}$ This type of impairment in neuromuscular activation would account for the CAI patients' inability to achieve full, voluntary activation of 
"Isokinetic Testing of Evertor and Invertor Muscles in Patients with Chronic Ankle Instability" by David P et al. Journal of Applied Biomechanics

(C) 2013 Human Kinetics, Inc.

the evertor and invertor muscles during maximal eccentric contractions. Recent studies support the hypothesis whereby arthrogenic muscle inhibition is caused by a change in the discharge of sensory receptors in the damaged joint, which influences the excitability of the $\alpha$-motoneuron pool via changes in spinal and supraspinal motor mechanisms ${ }^{38}$. Abnormal afferent discharge from the ankle would impair the motor control of evertors more than that of invertors. On the basis of several reports, ${ }^{12,39}$ a reorganization of the peripheral motor function (notably involving the control of proprioceptive sensory afferences from muscle and tendon receptors) can be suspected and may account for the pronounced, peripheral inhibiting mechanisms in patients with CAI. Alternatively, as earlier suggested by $\operatorname{Tropp}^{40}$ and illustrated in part by the subjects' fear of making maximal eccentric efforts after suffering from ankle injury, central adaptations of leg muscle control in patients with CAI should also be considered when accounting for impaired eccentric strength. In view of our suggestion that ankle instability may be linked to neural drive rather than muscle impairment, CAI rehabilitation programs should focus on the motor control of eccentric contractions of the ankle evertors and invertors, in order to boost these muscles' contributions to ankle stability.

\section{Acknowledgements}

The authors are greatly indebted to Momar Diouf for invaluable assistance with the statistical analysis and David Fraser for English language revision of the manuscript. 
"Isokinetic Testing of Evertor and Invertor Muscles in Patients with Chronic Ankle Instability" by David P et al. Journal of Applied Biomechanics

(C) 2013 Human Kinetics, Inc.

\section{References}

1. Fong DT, Hong Y, Chan LK, et al. A systematic review on ankle injury and ankle sprain in sports. Sports Med. 2007;37(1):73-94.

2. Delahunt E, Coughlan GF, Caulfield B, et al. Inclusion criteria when investigating insufficiencies in chronic ankle instability. Med Sci Sports Exerc. 2010;42(11):21062121.

3. Suda EY, Amorim CF, Sacco Ide C. Influence of ankle functional instability on the ankle electromyography during landing after volleyball blocking. J Electromyogr Kinesiol. 2009;19(2):84-93.

4. Webster KA, Gribble PA. Functional rehabilitation interventions for chronic ankle instability: a systematic review. J Sport Rehabil. 2010;19(1):98-114.

5. Hertel J. Functional anatomy, pathomechanics, and pathophysiology of lateral ankle instability. J Athl Train. 2002;37(4):364-375.

6. Tropp H. Commentary: functional ankle instability revisited. $J$ Athl Train. 2002;37(4):512-515.

7. Loudon JK, Santos MJ, Franks L, et al. The effectiveness of active exercise as an intervention for functional ankle instability: a systematic review. Sports Med. 2008;38(7):553-563.

8. Arnold BL, Linens SW, de la Motte SJ, et al. Concentric evertor strength differences and functional ankle instability. J Athl Train. 2009;44(6):653-662.

9. Hiller CE, Nightingale EJ, Lin CW, et al. Characteristics of people with recurrent ankle sprains: a systematic review with meta-analysis. $\mathrm{Br} J$ Sports $\mathrm{Med}$. 2011;45(8):660-672.

10. Delahunt E. Neuromuscular contributions to functional instability of the ankle joint. $J$ Bodyw Mov Ther. 2007;11(3):203-213.

11. Sefton JM, Hicks-Little CA, Hubbard TJ, et al. Sensorimotor function as a predictor of chronic ankle instability. Clin Biomech (Bristol, Avon). 2009;24(5):451-458.

12. Hass CJ, Bishop MD, Doidge D, et al. Chronic ankle instability alters central organization of movement. Am J Sports Med. 2010;38(4):829-834.

13. Munn J, Sullivan SJ, Schneiders AG. Evidence of sensorimotor deficits in functional ankle instability: a systematic review with meta-analysis. J Sci Med Sport. 2010;13(1):2-12.

14. Mora I, Quinteiro-Blondin S, Pérot C. Electromechanical assessment of ankle stability. Eur J Appl Physiol. 2003;88(6):558-564. 
"Isokinetic Testing of Evertor and Invertor Muscles in Patients with Chronic Ankle Instability" by David P et al.

Journal of Applied Biomechanics

(c) 2013 Human Kinetics, Inc.

15. Caulfield B, Garrett M. Changes in ground reaction force during jump landing in subjects with functional instability of the ankle joint. Clin Biomech (Bristol, Avon). 2004;19(6):617-621.

16. Hertel J, Olmsted-Kramer LC. Deficits in time-to-boundary measures of postural control with chronic ankle instability. Gait Posture. 2007;25(1):33-39.

17. McVey ED, Palmieri RM, Docherty CL, et al. Arthrogenic muscle inhibition in the leg muscles of subjects exhibiting functional ankle instability. Foot Ankle Int. 2005;26(12):1055-1061.

18. Sedory EJ, McVey ED, Cross KM, et al. Arthrogenic muscle response of the quadriceps and hamstrings with chronic ankle instability. $J$ Athl Train. 2007;42(3):355-360.

19. DeVries HA. "Efficiency of electrical activity" as a physiological measure of the functional state of muscle tissue. Am J Phys Med. 1968;47(1):10-22.

20. Docherty CL, Gansneder BM, Arnold BL, et al. Development and reliability of the ankle instability instrument. J Athl Train. 2006;41(2):154-158.

21. Hermens HJ, Freriks B, Disselhorst-Klug C, et al. Development of recommendations for SEMG sensors and sensor placement procedures. J Electromyogr Kinesiol. 2000;10(5):361-374.

22. McNair PJ, Depledge J, Brettkelly M, Stanley SN. Verbal encouragement: effects on maximum effort voluntary muscle action. Br J Sports Med. 1996;30(3):243-245.

23. Baltzopoulos V, Williams JG, Brodie DA. Sources of error in isokinetic dynamometry: effects of visual feedback on maximum torque. J Orthop Sports Phys Ther. 1991;13(3):138-142.

24. Parcell AC, Sawyer RD, Tricoli VA, et al. Minimum rest period for strength recovery during a common isokinetic testing protocol. Med Sci Sports Exerc. 2002;34(6):10181022.

25. Pousson M, Lepers R, Van Hoecke J. Changes in isokinetic torque and muscular activity of elbow flexors muscles with age. Exp Gerontol. 2001;36(10):1687-1698.

26. Cohen J. Statistical power analysis for the behavioral sciences, 2nd ed. Hillsdale, NJ: Lawrence Erlbaum Associates; 1988.

27. Bosien WR, Staples OS, Russel SW. Residual disability following acute sprains. $J$ Bone Joint Surg Am. 1955;37A:1237-1243.

28. Munn J, Beard DJ, Refshauge KM, et al. Eccentric muscle strength in functional ankle instability. Med Sci Sports Exerc. 2003;35(2):245-250. 
"Isokinetic Testing of Evertor and Invertor Muscles in Patients with Chronic Ankle Instability" by David P et al.

Journal of Applied Biomechanics

(c) 2013 Human Kinetics, Inc.

29. Willems T, Witvrouw E, Verstuyft J, et al. Proprioception and muscle strength in subjects with a history of ankle sprains and chronic instability. J Athl Train. 2002;37(4):487-493.

30. Holmes A, Delahunt E. Treatment of common deficits associated with chronic ankle instability. Sports Med. 2009;39(3):207-224.

31. Hopkins JT, Ingersoll CD. Arthrogenic muscle inhibition: a limiting factor in knee joint rehabilitation. J Sport Rehabil. 2000;9(2):135-159.

32. Kaminski TW, Hartsell HD. Factors contributing to chronic ankle instability: A strength perspective. J Athl Train. 2002;37(4):394-405.

33. Monaghan K, Delahunt E, Caulfield B. Ankle function during gait in patients with chronic ankle instability compared to controls. Clin Biomech (Bristol, Avon). 2006;21(2):168-174.

34. Delahunt E, Monaghan K, Caulfield B. Changes in lower limb kinematics, kinetics, and muscle activity in subjects with functional instability of the ankle joint during a single leg drop jump. J Orthop Res. 2006;24(10):1991-2000.

35. Barnes WS. The relationship of Motor-unit activation to isokinetic muscular contraction at different contractile velocities. Phys Ther. 1980;60(9):1152-1158.

36. Freeman MA, Dean MR, Hanham IW. The etiology and prevention of functional instability of the foot. J Bone Joint Surg Br. 1965;47(4):678-685.

37. Sjölander P, Johansson H, Djupsjöbacka, M. Spinal and supraspinal effects of activity in ligament afferents. J Electromyogr Kinesiol. 2002;12(3):167-176.

38. Rice DA, McNair PJ. Quadriceps arthrogenic muscle inhibition: neural mechanisms and treatment perspectives. Semin Arthritis Rheum. 2010;40(3):250-266.

39. Kapreli E, Athanasopoulos S, Gliatis J, et al. Anterior cruciate ligament deficiency causes brain plasticity: a functional MRI study. Am J Sports Med. 2009;37(12):24192426.

40. Tropp H. Pronator muscle weakness in functional instability of the ankle joint. Int $J$ Sports Med.1986;7(5):291-294. 
"Isokinetic Testing of Evertor and Invertor Muscles in Patients with Chronic Ankle Instability" by David P et al. Journal of Applied Biomechanics

(C) 2013 Human Kinetics, Inc.
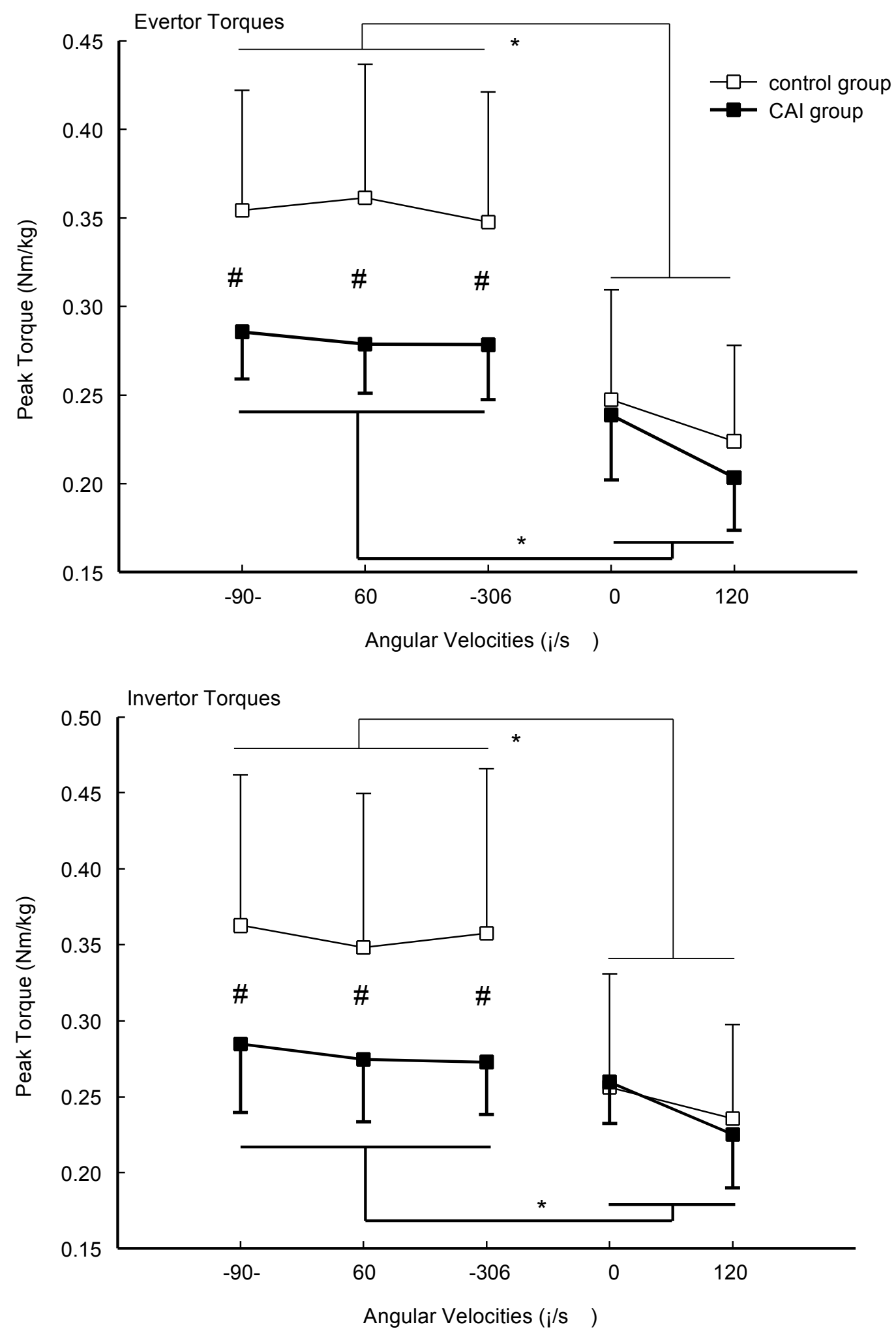

Figure 1 - Normalized peak torque values measured during eccentric contraction (negative angular velocities) and concentric contraction (positive angular velocities). Mean value and one standard deviation are shown. * and \# denote significant differences with $P<.0001$ and $P<.01$, respectively. 
"Isokinetic Testing of Evertor and Invertor Muscles in Patients with Chronic Ankle Instability" by David P et al. Journal of Applied Biomechanics

(C) 2013 Human Kinetics, Inc.
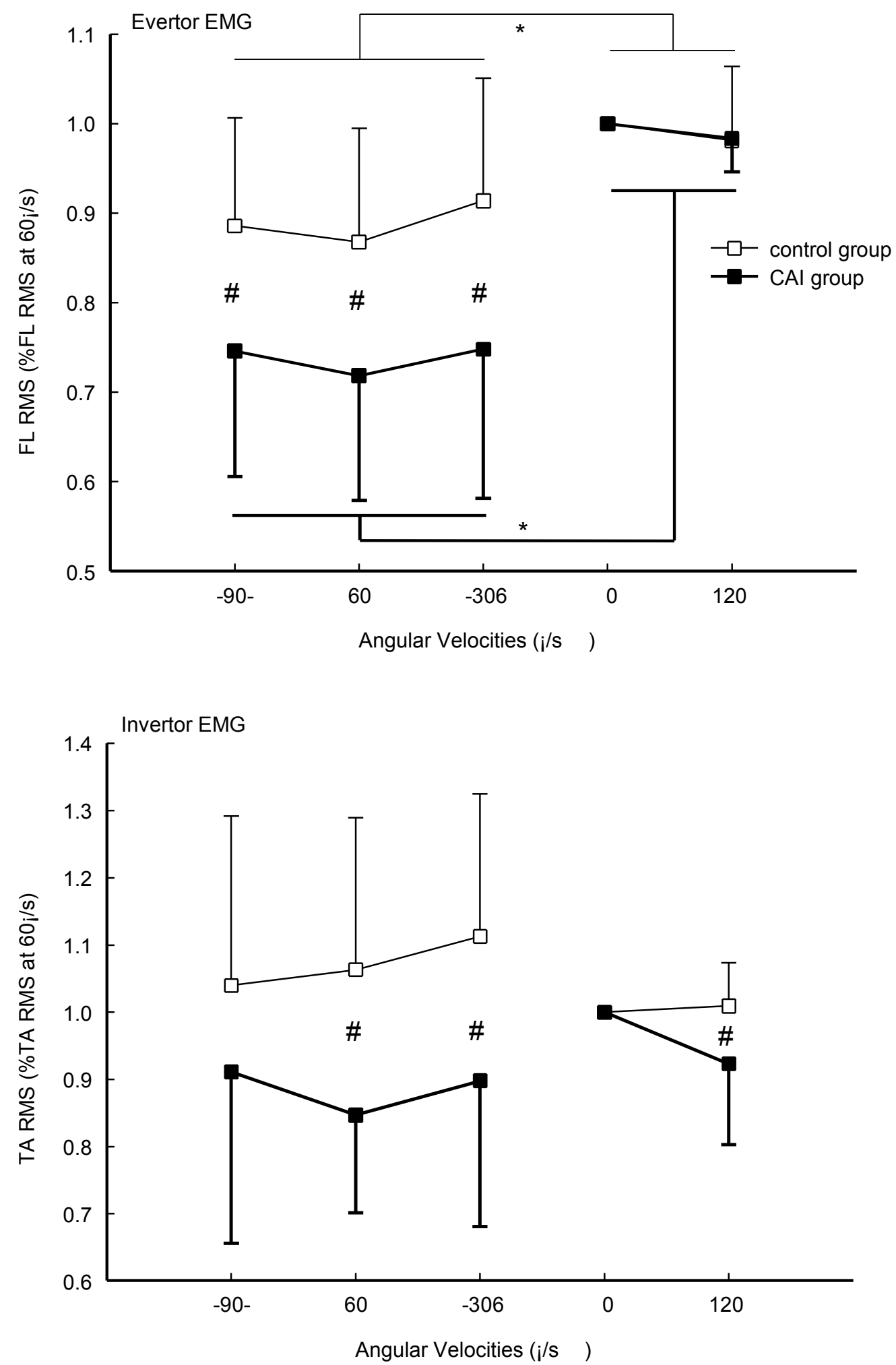

Figure 2 - EMG activities recorded during eccentric contraction (negative angular velocities) and concentric contraction (positive angular velocities). Mean value and one standard deviation are represented. $*$ and \# denote significant differences with $P<.001$ and $P<.05$, respectively. 
"Isokinetic Testing of Evertor and Invertor Muscles in Patients with Chronic Ankle Instability" by David P et al. Journal of Applied Biomechanics

(C) 2013 Human Kinetics, Inc.
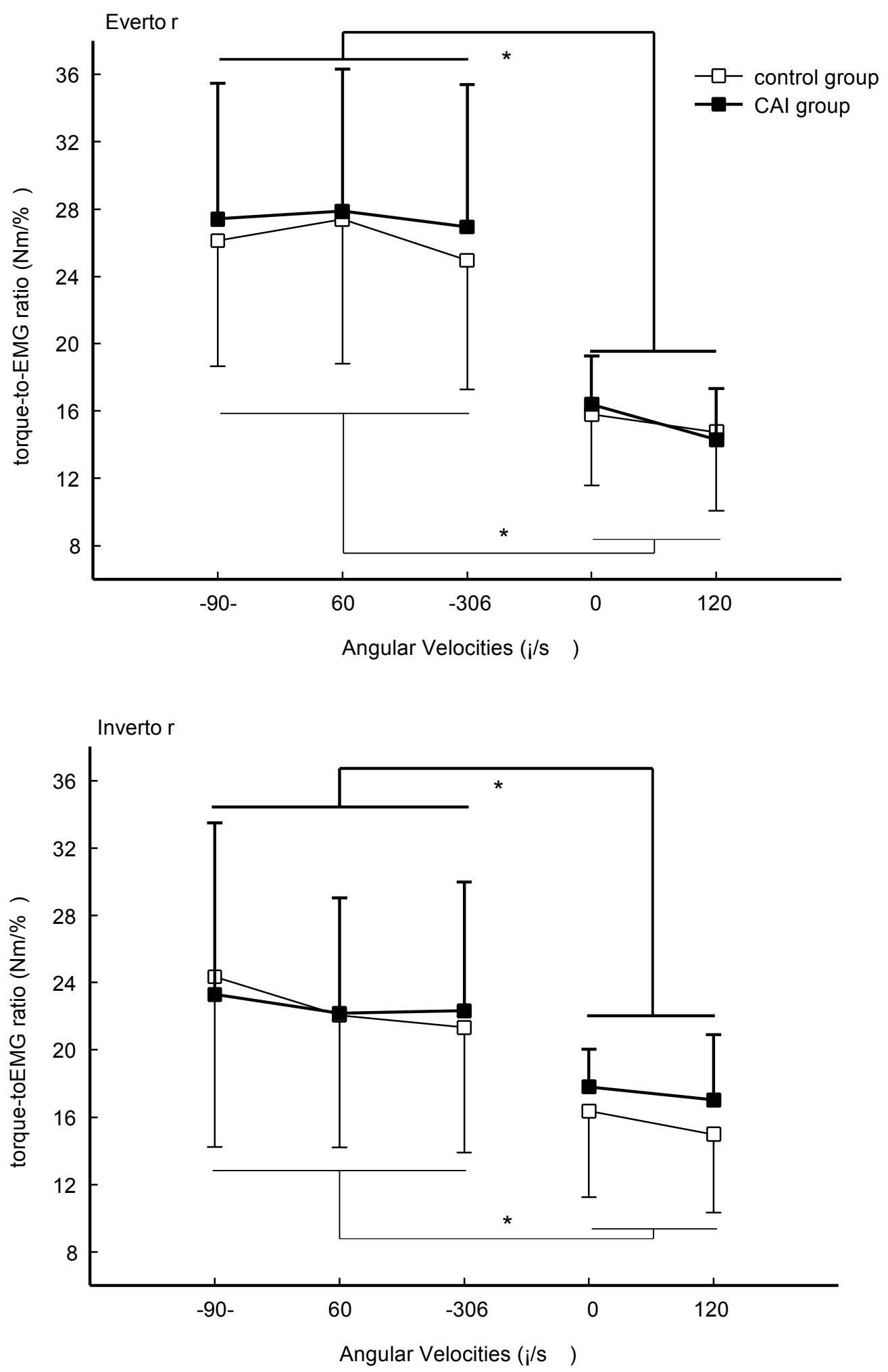

Figure 3 - The torque-to-EMG ratios calculated during eccentric contraction (negative angular velocities) and concentric contraction (positive angular velocities). Mean value and one standard deviation are represented. * denotes significant differences with $P<.01$. 


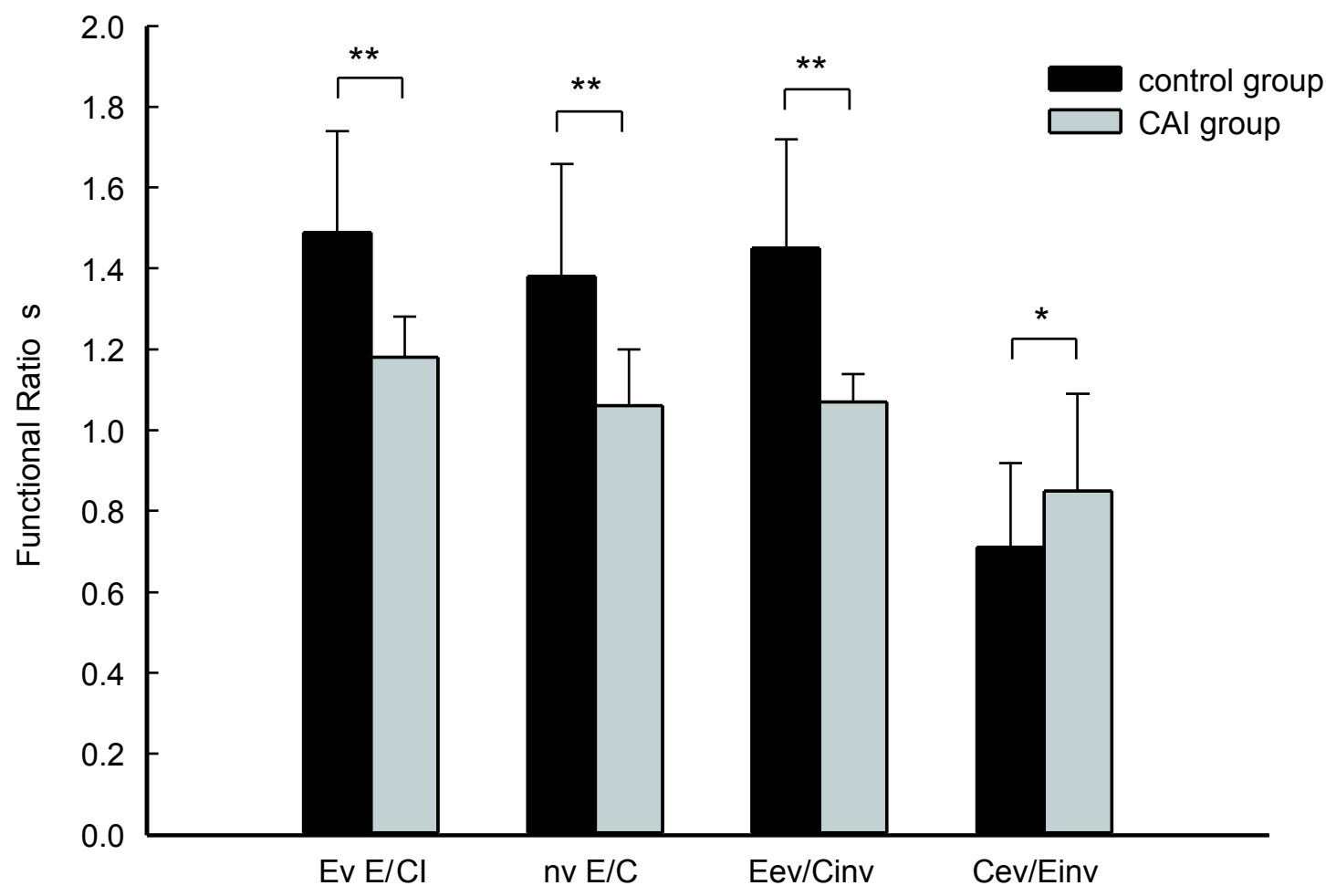

Figure 4 - Eccentric to concentric ratios for evertors (Ev E/C) and invertors (Inv E/C), the eccentric evertor to concentric invertor ratio (Eev/Cinv) and the concentric evertor to eccentric invertor ratio (Cev/Einv). Mean value and one standard deviation are represented. * and $* *$ denote significant intergroup differences with $P<.05$ and $P<.01$, respectively. 
"Isokinetic Testing of Evertor and Invertor Muscles in Patients with Chronic Ankle Instability" by David P et al. Journal of Applied Biomechanics

(C) 2013 Human Kinetics, Inc.

Table 1 The study participants' characteristics $(n=24$; data are presented as the mean \pm standard deviation)

\begin{tabular}{|ccc|c|c|}
\hline & \multicolumn{2}{c}{ CAI group $(n=12)$} & \multicolumn{2}{c}{ Control group $(n=12)$} \\
\cline { 2 - 5 } \multicolumn{1}{c|}{} & Men $(n=8)$ & Women $(n=4)$ & Men $(n=6)$ & Women $(n=6)$ \\
\hline Age (years) & $21.3 \pm 1.8$ & $23.5 \pm 4.4$ & $22.5 \pm 2.4$ & $24.0 \pm 3.0$ \\
\hline Weight $(\mathrm{kg})$ & $72.8 \pm 8.5^{*}$ & $58.8 \pm 7.0$ & $66.2 \pm 11.6$ & $57.8 \pm 10.7$ \\
\hline Height $(\mathrm{m})$ & $1.81 \pm 0.07^{*}$ & $1.68 \pm 0.09$ & $1.76 \pm 0.08$ & $1.69 \pm 0.10$ \\
\hline BMI** $\left(\mathrm{kg} / \mathrm{m}^{2}\right)$ & $22.1 \pm 1.3$ & $20.8 \pm 1.5$ & $21.3 \pm 2.7$ & $20.1 \pm 1.6$ \\
\hline
\end{tabular}

Note. For the group of study participants as a whole $(n=24)$, independent-sample $t$ tests revealed significant differences $(P<.01)$ between men and women in terms of weight $(69.9$ $\pm 10.1 \mathrm{~kg}$ vs. $58.2 \pm 8.9 \mathrm{~kg}$, respectively $)$ and height $(1.79 \pm 0.08 \mathrm{~m} \mathrm{vs} .1 .69 \pm 0.09 \mathrm{~m}$ respectively). $*$ indicates a significant $(P<.05)$ male-female difference within the CAI group. ** body mass index 